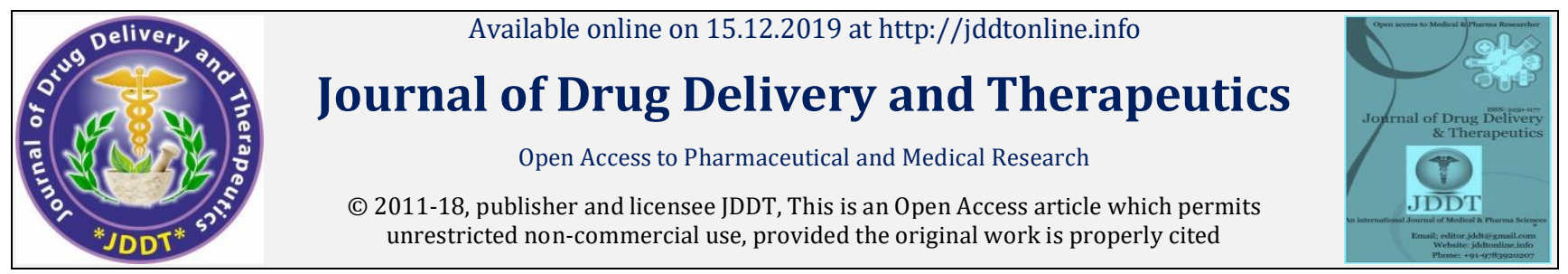

Open Access

Research Article

\title{
Identification and quantification of fruit phenolic compounds of Malus communis
}

\author{
Soulef Saoudi*, Seddik Khennouf, Nozha Mayouf \\ Laboratory of Phytotherapy Applied to Chronic Diseases, Faculty of Nature and Life Sciences, Univ Setif 1, 19000, Algeria
}

\begin{abstract}
Malus communis (apple) is fruits belong to family Rosaseae. Apple is important source of phytochemicals substance, which has good effect in human health and antioxidant activity. The aim of this work is to identify the polyphenols compounds and the antioxidant activity of Malus communis. The analyses phytochemicals of polyphenols is estimated by UPLC method. The flavonoids content were determinate by the Aluminum chloride method. The antioxidant activity was evaluated by the DPPH, ABTS and reducing power. The results suggested that Malus communis have high content of sugars, tannin (795 $\pm 0.05 \mathrm{mg}$ D- glucose equivalents per gram dry weight, $31.38 \pm 0.006 \mathrm{mg}$ tannic acid equivalents per gram dry weight and important amount of flavonoids $5.08 \pm 0.001$ mg quercetin equivalents per gram of dry weight) respectively. The chromatogram of apple demonstrated that this fruits contain various substances such as Gallic acid and Chlorogenic acid. The extract exerted good effect in antioxidant activity. Apple can scavenge free radicals ABTS and DPPH with values of IC $50(0.64 \pm 0.02,0.60 \pm 0.03$ $\mathrm{mg} / \mathrm{ml}$ respectively). Finally the consumption dietary of fruits can reduce the risk the chronic disease.

Keywords: Malus communis, UPLC, tannin, flavonoids, antioxidant activity.
\end{abstract}

Article Info: Received 12 Aug 2019; $\quad$ Review Completed 11 Oct 2019; $\quad$ Accepted 28 Oct 2019; Available online 15 Dec 2019

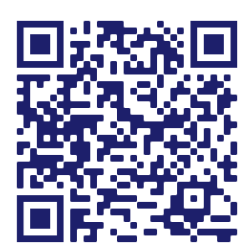

Cite this article as:

Saoudi S, Khennouf S, Mayouf N, Identification and quantification of fruit phenolic compounds of Malus communis, Journal of Drug Delivery and Therapeutics. 2019; 9(6-s):1-4 http://dx.doi.org/10.22270/jddt.v9i6-s.3264

*Address for Correspondence:

Saoudi Soulef, Laboratory of Phytotherapy Applied to Chronic Diseases, Faculty of Nature and Life Sciences, Univ Setif 1, 19000, Algeria

\section{INTRODUCTION}

Free radicals are normal molecules product by cell body. These compounds are very reactive and have important role in natural processes [1]. The high level of free radical induced stress oxidative which associated with various diseases such as cancers, atherosclerosis, arthritis, stroke, asthma [2]. Fruits and vegetables may play an important role to decrease of the mortality rate of cardiovascular and reduce blood pressure and others diseases [3]. This positive influence is attributed to some natural antioxidant phytonutrients [4]. The most thoroughly investigated dietary compounds in fruits acting as antioxidant are fiber, polyphenols, flavonoids and vitamins [5]. The amount of polyphenols is very important than the ascorbic acid in fruits and have good antioxidant activity [6]. Polyphenols act as anticancer or cardio-protective agents by a variety of mechanisms [7]. In this research, the apple used and is growing in Algeria. It has high nutritional value with reasonable amounts of sugars, amino acids and minerals like sodium, potassium, calcium, magnesium and iron [8]. It has also higher dietary fiber level than most common fruits and vegetables, giving excellent results in the treatment of constipation and intestine inflammation [9]. Apple also contain other nutritional and bioactive components as polyphenols [10]. The aim of this study is the determination, analysis of polyphenols compounds and evaluates the antioxidant activity in vitro of Apple fruit extract. The continuous eating of fruits reduces the incidence of serious diseases.

\section{MATERIALS AND METHODS}

Fruits materials

The fruits of Malus communis were purchased from commercial market in Amoucha from Setif (Algeria). In this study, the fruit used freshly.

\section{Preparation of extract}

The extract fruit was obtained according the method of Markham [11]. 100g of fruits after homogenized mixed with $1 \mathrm{~L}$ methanol- water $(85: 15 \mathrm{v} / \mathrm{v}, 50: 50 \mathrm{v} / \mathrm{v})$. After 5 day the mixture was filtered. The supernatant was evaporated using vacuum rotary evaporator at $40 \mathrm{C}^{\circ}$.

\section{Identification of polyphenols}

A ultra -performance liquid chromatographic method equipped with diode-array detection was used to identified the major phenolic compounds (gallic acid, naringenin, chlorogenic, catechin, syringic acid) in apple. Chromatographic separation was performed on a Hypersil column $\left(1.9 \mu \mathrm{m}^{*} 3 \mathrm{~nm} * 50 \mathrm{~mm}\right)$. The flow rate was kept 
constant throughout the analysis at $0.6 \mathrm{ml} / \mathrm{min}$ and the injection volume was $20 \mu \mathrm{l}$. The operating condition were as follows: mobile phase water (A) and acetonitrile (B): gradiant $5 \%$ B from 0 to $1 \mathrm{~min}, 5 \%-21 \%$ B from 1 to $5 \mathrm{~min}$, $21 \%-50 \%$ B from 5 to $7 \mathrm{~min}, 50 \%-100 \%$ B from 7 to $10 \mathrm{~min}$ $5 \%$ B from 10 to 13 min. The column was maintained at $30^{\circ}$ and UV detection was recorded in the range $165 \mathrm{~nm}-365$ $\mathrm{nm}$. The peak identification in samples was also based on comparisons of the retention times (TR) of the isolated phytochemical standards.

\section{Total flavonoids contents}

The total flavonoids content was determined by the using the Aluminum chloride colorimetric method of Bahromun [12]. The standard curve was prepared using $0-40 \mu \mathrm{g} / \mathrm{ml}$ solution of Quercetin. The results are expressed in milligram of quercetin equivalent per gram dried extract.

\section{Tannin content}

The determination of tannin content is based to the capacity of these compounds for precipitate the hemoglobin. The amount of tannin was estimated according the method of Gharzouli et al [13] and they was expressed as mg equivalent tannic acid /g dry extract.

\section{Total soluble sugars content in the fruit extract}

The total sugars content was determined using the method of Dubois et al [14]. The amount of sugar was expressed in $\mathrm{mg} / \mathrm{g}$ dried weight.

\section{In vitro antioxidant activity \\ DPPH radical scavenging activity}

The ability of fruit extract to scavenge DPPH radicals was estimated by the procedure of Yardpiroom [15]. A $0.5 \mathrm{ml}$ of extract with different concentration was mixed with $1 \mathrm{ml}$
DPPH solution $(0.1 \mathrm{Mm})$. After $30 \mathrm{~min}$ of incubation, the absorbance was recorded at $517 \mathrm{~nm}$. The percentage inhibition was calculated using the following formula.

Percentage inhibition $=\left(\mathrm{Abs}_{\text {control }}-\mathrm{Abs}_{\text {sample }}\right) / \mathrm{Abs}_{\text {control }}$ *100. The concentration having $50 \%$ radical inhibition activity (IC50) expressed as mg extract/ml.

\section{ABTS radical scavenging activity}

The method used was described by Re et al [16]. This assay is based the ability of extract to inhibit the ABTS radical compared the reference standard vitamin $C$. The stock solution of ABTS was prepared by the mixed of ABTS $(7 \mathrm{mM})$ and $2.45 \mathrm{mM}$ potassium persulfate. After $16 \mathrm{~h}$ of incubation the mixture was diluted by the methanol to give $0.7 \pm 0.02$ absorbance at $734 \mathrm{~nm} .50 \mu \mathrm{l}$ of extract was added to $1 \mathrm{ml}$ of ABTS solution. After 30 min of incubation in the dark at temperature room, the absorbance was measured at $734 \mathrm{~nm}$. The percentage inhibition was calculated by the same equation of DPPH assay.

\section{Statistical analysis}

The result was expressed in the Mean \pm SD. All analyses were determined by the Graph pad (version 5).

\section{RESULT AND DISCUSSION}

\section{Identification of polyphenols}

The UPLC chromatogram of Malus communis fruit extract belong to Rosaseae family revealed the presence of various phenolic acid and flavonoids such as gallic acid, protocachuic acid, Syringic acid, naringenin. The phenolic compounds were identified according to their retention times, molecular masses, fragmentation patterns, characteristic spectra, and bibliographical sources. The compound major in this family is Gallic and protocachuic acid.

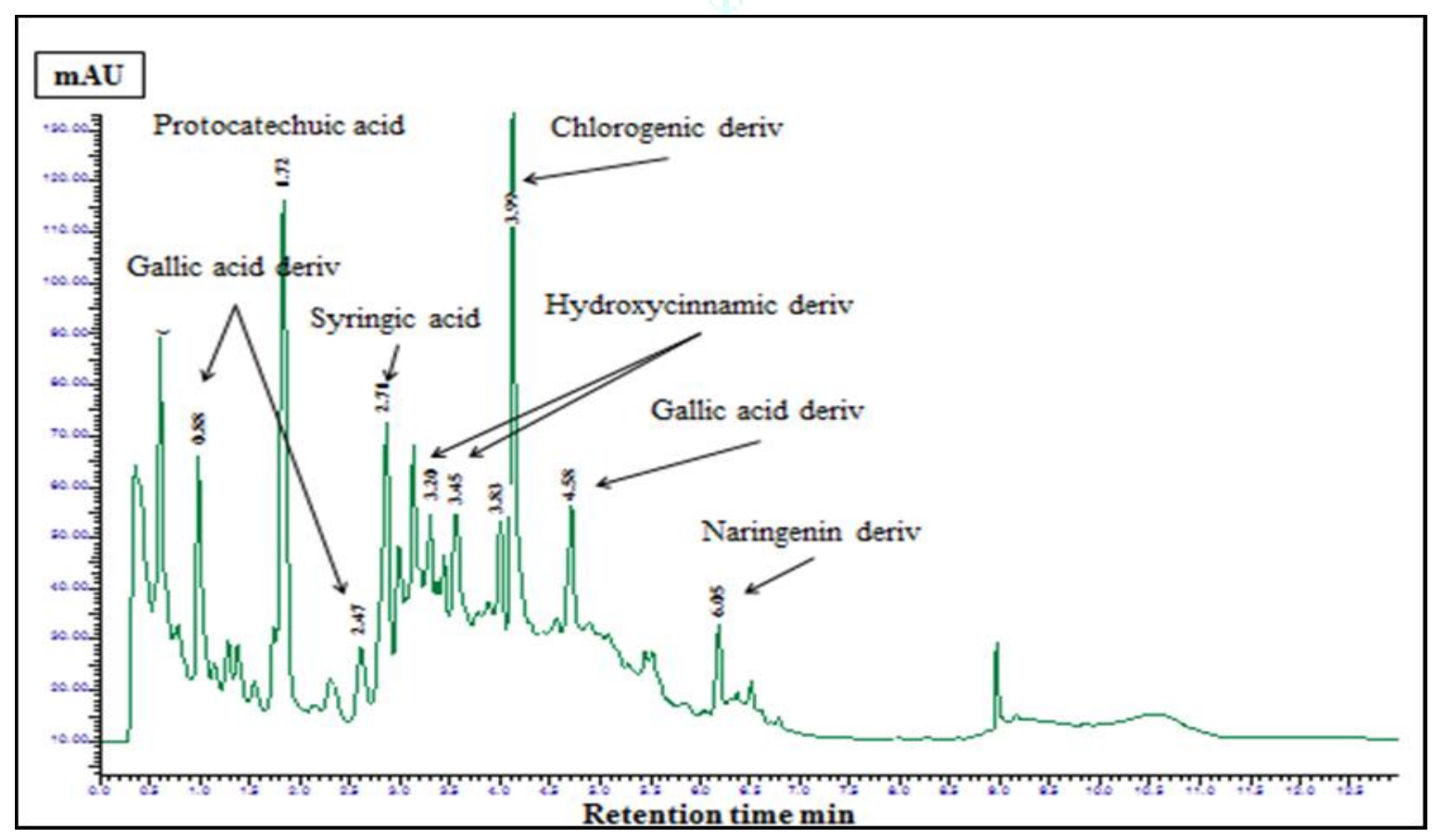

Figure 1: UPLC chromatogram of Malus communis fruit methanol extract. 
Total flavonoids, tannin content and total sugars in the fruit extract.

Apple is good source of phytochemicals such as phenolic compounds. Which have good health benefits [17]. Those health benefits of polyphenol consumption originate from their antioxidant properties [18]. Flavonoids are the most and important group of phenolic compounds, which are characterized by a benzo-pyrone structure [19]. The total flavonoid content was expressed as mg quercetin equivalents $(\mathrm{QE}) / \mathrm{g}$ sample. Tannins are naturally occurring phenolic compounds which precipitate protein. Which are found in legumes and fruits and important source of dietary antioxidant [20].

The total flavonoids, tannin and total sugars were calculated from the regression equation of calibration curve $(y=$ $0.035 x-0.046, R^{2}=0.996 ; y=-0.0021 x+1.4181, R^{2}=0.988 ; y=$ $\left.0.0107 x+0.157, R^{2}=0.994\right)$ respectively. Table 1 represented the amount of flavonoids, tannin and total sugars in Malus communis. The result showed that the apple extract contained high level of sugars $795 \pm 0.05$ flowed by tannin and flavonoids with values $(31.38 \pm 0.006 \mathrm{mg}$ TAE$/ \mathrm{g} 5.08$ $\pm 0.001 \mathrm{mg} \mathrm{QE} / \mathrm{g}$ ) respectively.

Table 1: flavonoids and tannins contents and total sugars in fruits extracts.

\begin{tabular}{|l|l|l|l|}
\hline Extract & Total sugar (mg d-glucose E/g) & Total flavonoids (mg QE/g) & Total tannins (mg TAE/g) \\
\hline Malus communis & $795 \pm 0.05$ & $5.08 \pm 0.001$ & $31.38 \pm 0.006$ \\
\hline
\end{tabular}

QE : Quercetin Equivalent. TAE : Tannic Acid Equivalent. Results expressed as means \pm SD.

Secondary plant metabolites, such as flavonoids or tannins, can be also involved in complex system of antioxidant defense. The basic mechanisms of antioxidant activity of tannins are free radical scavenging activity, chelation of transition metals and inhibition of prooxidative enzymes. Tannins show various health benefit activities, especially antioxidant, antitumor, cardioprotective, anti-inflammatory and antimicrobial activity [21]. There is some research showed that sugars having antioxidant activity and the mechanisms of sugars for exerted the antioxidant effect is not clearly [22, 23].

\section{In vitro antioxidant activity}

\section{DPPH radical scavenging activity}

DPPH is commercially stable free radical with purple colour. Generally used for evaluated the scavenging activity. This method based the reduction of DPPH solution by the hydrogen and electron donating antioxidant present in the extract, and the formation of new molecule (biphenyl hydrazine), which have yellow colour. The change of colour is result of scavenging of DPPH by the antioxidant. DPPH molecule have high absorbance at $517 \mathrm{~nm}$ which decreased when DPPH accept electron or hydrogen [24, 25]. Figure1. Present the percentage inhibition of DPPH by fruit extract and standard. The results show that fruit extract and BHT can reduce the signal intensity of DPPH and their radicalscavenging activities increased with increasing concentration.

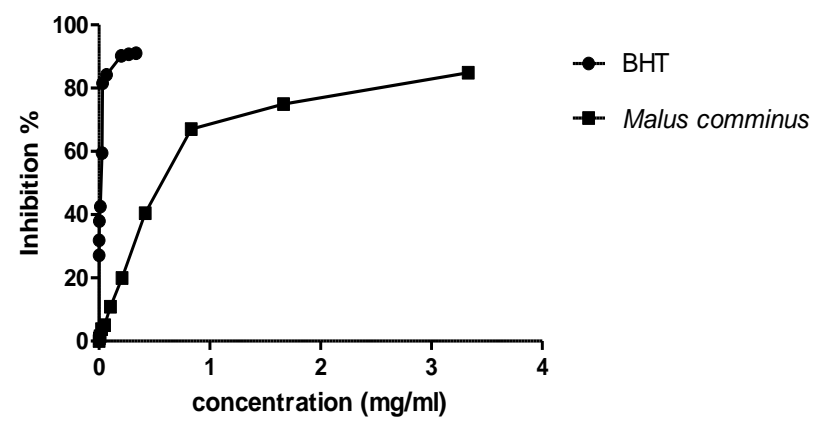

Figure 2: DPPH free radical scavenging activity of fruit extract and standard.

\section{ABTS radical scavenging activity}

In this assay, the 2,2'-azino-bis(3-ethylbenzthiazoline-6sulfonic acid) (ABTS) radical, which has a peak absorbance at $734 \mathrm{~nm}$, should be performed by mixing ABTS and potassium persulfate $\left(\mathrm{K}_{2} \mathrm{~S}_{2} \mathrm{O} 8\right)$. When antioxidants were added, the ABTS radical, which has a blue-green colour, is reduced to ABTS (no colour) [26]. The ABTS activity was quantified in terms of percentage inhibition of the ABTS radical cation by antioxidant in sample. Figure 2 . Shows the ABTS scavenging abilities of apple and reference standards. At $0.01 \mathrm{mg} / \mathrm{ml}$ apple extract reduced ABTS only $10 \%$ compared Vit C reduced $92 \%$.

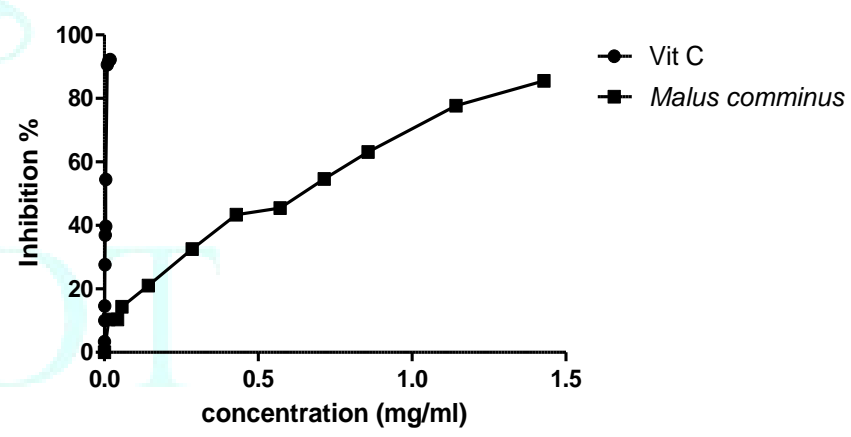

Figure 3: ABTS free radical scavenging activity of fruit extract and standard.

\section{CONCLUSION}

In conclusion, fruit extract used in the present study were grown in Algeria. This fruit is widely consumed by the Algerian population. This fruit contain appreciable amounts of total flavonoids and tannins which are responsible for the in vitro properties of these fruits and their consumption can reduce cardiovascular diseases and other pathologies associated with free radicals.

\section{REFERENCES}

1. Das Sarma, A., Rahaman Mallick, A.R. and Ghosh, A.K. (2010). Free Radicals and Their Role in Different Clinical Conditions: An Overview"', IJPSR, 1.185-192.

2. Sabry, M. EL. (2013). Biochemistry of free radicals and oxidative stress. sciences international, 1(5).111-1117.2013.

3. Gorinstein, Sh., Zachwieja, Z., Katrich, E., Pawelzik, E., Haruenkit, R., Trakhtenberg S. and Martin-Belloso, O. (2004). Comparison 
of the contents of the main antioxidant compounds and the antioxidant activity of white grapefruit and his new hybrid. Lebensm.-Wiss. u.-Technol, 37. 337-343.

4. Miller, E.R., Appel, L.J. and Risby, T. H. (1998). Effect of dietary patterns on measures of lipidperoxidation: Results from a randomized clinical trial", Circulation, 98. 2390-2395.

5, 7. Kaur, Ch., and Kapoor, H.C. (2001). Antioxidants in fruits and vegetables - the millennium's health. J food sci and technology, 36: 703- 725 .

6. Deighton, N., Brennan, R., Finn, C. and Davies, H.V. (2000) Antioxidant properties of domesticated and wild Rubus species. Journal of the Science of Food and Agriculture, 80.107-1313.

8. Yim, S.-H., and Nam, S.-H. (2016). Physiochemical, nutritional and functional characterization of 10 different pear cultivars (Pyrus spp.). Journal of Applied Botany and Food Quality. 2016: 089009

9. Silva, G. J., Souza, T. M., Barbieri, R. L., and Costa de Oliveira, A. (2014). Origin, Domestication, and Dispersing of Pear (Pyrus spp.). Advances in Agriculture. 2014: 8.

10. Henríquez, C., Almonacid, S., Chiffelle, I., Valenzuela, T., Araya, M., Cabezas, L., Simpson, R. and Speisky, H. (2010). Determination of antioxidant capacity, total phenolic content and mineral composition of different fruit tissue of five apple cultivars grown in chile, Chilean journal of agricultural research, $70(4): 523-536$.

11. Markham KR (1982). Techniques of Flavonoid Identification (Chap.1 and 2). London: Academic Press Pp.1- 113.

12. Bahorun, T., Gressier B, Trotin F, Brunete C, Dine T, Vasseur J, Luyckx M, Cazin M, Pinkas M (1996). Oxygen species scavenging activity of phenolic extract from Hawthorn fresh plant organs and pharmaceutical preparations .Arzneim Forsch/Drug Res. 46: 1086-1089.

13. Gharzouli, K., Khennouf, S., Amira S, and Gharzouli A (1999). Effects of aqueous extracts from Quercus ilex L. root bark, Punica granatum L. fruit peel and Artemisia herba-alba Asso leaves on ethanol-induced gastric damage in rats. Phytother Res. 13: $42-45$.

14. Dubois M, Gilis K, Hamilton J, Rebers P, Smith F (1956). Colorimetric method for determination of sugars and related substances. Anal chem 28: 350-356.
15. Yardpiroon B, Aphidech S, Prasong S (2014). Phytochemical and Biological Activities of the Wild Grape Fruit Extracts Using Different Solvents. British J of Pharmaceutical Res 4: 23-36

16. Re R, (1999). Antioxidant activity applying an improved ABTS radical cation decolorization assays. Free Radic Biol Med 26: 1231-1237.

17. Kolniak-Ostek, J. (2016). Chemical composition and antioxidant capacity of different anatomical parts of pear (Pyrus communisL.). Food Chemistry. 203: 491-497.

18. Borges, G., Mullen, W., and Crozier, A. (2010). Comparison of the polyphenolic composition and antioxidant activity of European commercial fruit juices. Food \& Function, 1, 73-83.

19. Bakar, M.F.A., Mohamed, M., Rahmat, A. and Fry, J. (2009). Phytochemicals and antioxidant activity of different parts of bambangan (Mangifera pajang) and tarap (Artocarpus odoratissimus). Food Chemistry. 113: 479-483.

20. Hagerman, A.E., Ken M. Riedl, G. Kara N. A.J. Nicole T.S. Paul W. R., and Thomas L. Riechel . Th.L. (1998). High Molecular Weight Plant Polyphenolics (Tannins) as Biological Antioxidant. J. Agric. Food Chem. 46:1887-1892.

21. Koleckar, V., Katerina Kubikova, K., Rehakova, Z., Kamil Kuca, K. Jun D., Jahodar, L., and Opletal, L. (2008). Condensed and Hydrolysable Tannins as Antioxidants Influencing the Health. Mini-Reviews in Medicinal Chemistry. 8: 436-447.

22. Faraji, H and Lindsay, R.C. (2004). Characterization of the Antioxidant Activity of Sugars and Polyhydric Alcohols in Fish Oil Emulsions. J. Agric. Food Chem. 52: 7164-7171.

23. Dudonné, S., Vitrac, X., Coutiére, P., Woillez, M., and Mérillon, J. M. (2009). Comparative study of antioxidant properties and total phenolic content of 30 plant extracts of industrial interest using DPPH, ABTS, FRAP, SDD and DRAC assays. Journal of Agricultural and Food Chemistry. 57(5): 1768-1774.

24. Gulcin, I., Huyut, Z., Elmastas, M., and Aboul-Enein, H. Y. (2010). Radical scavenging and antioxidant activity of tannic acid. Arabian Journal of Chemistry. 3: 43-53.

25. Sheikh, M. V., Devadiga, N., and Hate, M. (2016). An in-vitro antiinflammatory and anti-oxidant activity of Anisomeles malabarica R.Br. Ex Sims. Journal of Chemical and Pharmaceutical Research. 8(4):1062-1067.

26. Li, W.J., Cheng , X.L., Liu, J., Lin, R.Ch., Wang, G. L., Shu Shan Du, S.Sh., and Liu, Z.L. (2012). Phenolic Compounds and Antioxidant Activities of Liriope muscari . Molecules. 17: 1797-1808. 